\title{
Sustentabilidade em Contexto Organizacional: UMA ANÁLISE COMPARATIVA DE MODELOS QUE PROPÕEM TRAJETÓRIAS PARA SUA GESTÃO
}

\author{
Sustainability in Organizational Context: a comparative analysis
}

of models that suggest paths for its management

\section{Luciano Munck}

Pós-Doutor - Ivey Business School - Western University - Canadá. Professor do Programa de Pós-graduação em Administração da Universidade Estadual de Londrina. Londrina, PR. Brasil.E-mail: munck@uel.br

\section{Ana Claudia Bansi}

Mestre em Administração. Professora do curso de Tecnólogo em Processos Gerenciais. Instituto Federal de São Paulo - Campus São Carlos. São Carlos, SP. Brasil. E-mail: ana_bansi@hotmail.com

\section{Barbara Galleli}

Universidade de São Paulo. Mestre em Administração. Professora do Centro Universitário SENAC-SP. São Paulo, SP. Brasil. E-mail: b.gallelidias@usp.br

\section{Resumo}

Este artigo, considerando a inexistência de fontes que sintetizam proposições de modelos para a gestão da sustentabilidade em contexto organizacional, depois de identificar cinco modelos, se propõe a comparar tais modelos fazendo uso de um quadro-referência criado para representar condições ideais de gestão da sustentabilidade nas organizações. Pela análise comparativa foram identificados avanços conceituais, convergências $e$ fragilidades. Uma das principais constatações denuncia a incompletude dos modelos. À medida que são comparados entre si e com o quadro-referência todos os modelos demonstraram falhar em algum aspecto basilar para o alcance da sustentabilidade organizacional. Percebeu-se a necessidade de maiores aprofundamentos quando se trata da implantação e da operacionalização de modelos de gestão da sustentabilidade nas organizações. Em suma, este estudo permitiu criar informações para a eliminação de fragilidades e para a sugestão de avanços. Isso pode orientar aprimoramentos cabíveis ao desenvolvimento de um framework global unificador das boas experiências para a gestão sistêmica e estrutural da sustentabilidade organizacional.

Palavras-chaves: Modelos. Gestão da Sustentabilidade. Sustentabilidade Organizacional.

\section{Abstract}

This article, considering the lack of sources that synthesize propositions models for sustainability management in an organizational context, after identifying five models, proposes to compare them making use of a reference frame created to represent ideal conditions for sustainability management in organizations. For the comparative analysis were identified conceptual advances, convergences, and weaknesses. A key finding reveals the incompleteness of the models. As they are compared with each other and with the reference frame all of them have shown fails in some fundamental respect for achieving organizational sustainability. It was realized the need for greater insights when it comes to deploying and operating models of sustainability management in organizations. In summary, this study provided to create information to eliminating weaknesses and to suggest improvements. This can guide improvements applicable to the development of a global unifying framework of good experiences to systemic and structural management organizational sustainability.

Keywords: Models. Sustainability Management. Organizational Sustainability. 


\section{INTRODUÇÃo}

As evolutivas discussões sobre sustentabilidade e desenvolvimento sustentável fazem emergir novas conclusões sobre os temas. Uma delas é a constatação de que o que antes era tido como uma responsabilidade central dos governos passa a ser uma responsabilidade central das organizações, em especial as privadas. $\mathrm{O}$ entendimento de que as organizações consomem deliberadamente e cotidianamente os recursos ambientais e sociais do mundo, frequentemente de forma desregrada, desigual e prejudicial, tem conduzido muitas organizações a repensarem seus processos produtivos. Com base neste entendimento, estudiosos e consultores empresariais visualizam a necessidade de melhor compreender quais mudanças seriam necessárias aos modelos de gestão para atender e englobar as premissas da sustentabilidade.

De acordo com Van Marrewijk (2003), tanto no âmbito dos debates acadêmicos, quanto no cenário empresarial, inúmeros conceitos são propostos para se fazer menção a processos de gestão que incorporem a sustentabilidade, mas ainda não há uma definição singular ou consensual para a sustentabilidade organizacional ou conceito semelhante. Apesar da grande variação de designações, os autores que firmam seus estudos sobre a sustentabilidade organizacional (BARONI, 1992; ELKINGTON, 1999; DILLYCK; HOCKERTS, 2002; HOFF, 2008; BARKEMEYER et al., 2014) convergem na ideia básica de que as atividades das organizações desenvolvem-se em um contexto que condiciona a qualidade e a disponibilidade de três elementos fundamentais para a gestão: o econômico, o ambiental e o social.

O conceito de desenvolvimento sustentável carece de meios de operacionalização e contextualização e de uma tradução de seus princípios gerais em práticas organizacionais. No entanto, alcançar a sustentabilidade não é uma tarefa trivial e sua incorporação nas organizações prescinde de uma abordagem pela qual ela não seja considerada uma mera "adição", mas seja sistematicamente integrada em todas as atividades organizacionais. Em outras palavras, a sustentabilidade organizacional demanda frameworks ou modelos de gestão que permitam à organização entender e agir em conformidade com as premissas da sustentabilidade, mensurar seu desempenho e avaliar seu progresso, bem como dispor de meios para comunicar aos seus stakeholders políticas e avanços em direção à sustentabilidade (AZAPAGIC, 2003; BARKEMEYER et al., 2014).

Porém, segundo Azapagic (2003), até o momento, não é possível identificar um framework global de gestão que permita tal abordagem sistêmica e estrutural para gerenciar a sustentabilidade organizacional. Embora haja um corpo substancial na literatura acerca de diferentes modelos, a compreensão deste fenômeno para o meio empresarial, assim como a ocorrência de sua operacionalização, ainda não se apresentam de forma significativa (STUBBS; COCKLIN, 2008). O fato é que em meio à propagação de novas práticas e estudos que buscam promover e/ou relatar a gestão sustentável, nota-se um maior número de iniciativas relacionadas a guias ou orientações para divulgação das ações organizacionais ditas sustentáveis, em lugar de novas estratégias de implementação, sistemas de mensuração e modelos gerenciais (HANH; SCHEEMESSER, 2005; VOS, 2007; BARKEMEYER et al., 2014; EWEJE, 2011).

Apoiado nas considerações anteriores, o presente artigo objetivou destacar e apresentar alguns dos principais modelos de gestão da sustentabilidade organizacional, encontrados a partir de uma pesquisa realizada na base de dados - Periódicos Capes. Foram selecionadas a área "Ciências Sociais Aplicadas" e a subárea "Administração de Empresas, Administração Pública, Contabilidade", sendo as bases escolhidas: EBSCO; ProQuest; Emerald; SAGE Journals Online; SciELO.ORG; e Web of Science. Buscou-se por artigos que relatassem a aplicação ou proposição de modelos de operacionalização da sustentabilidade em contexto organizacional, a partir das palavras-chave "sustentabilidade" e "modelo de gestão", bem como suas traduções para o inglês.

De um total de 38 artigos que tinham essa característica, foram destacados como os mais originais cinco modelos. Para esta seleção, foram observadas a teoria utilizada, a forma de abordagem proposta para o estudo das organizações, ou seja, sua aproximação com a realidade organizacional, e a abrangência sistêmica em relação a sustentabilidade, tendo em vista que diversos trabalhos limitavam-se à tratativa da dimensão ambiental. 
Dessa forma, objetiva-se comparar os modelos entre si, identificar avanços conceituais de um modelo em relação ao outro, bem como fragilidades, a partir de um quadro-referência criado para representar condições ideais de gestão da sustentabilidade nas organizações. Busca-se, assim, oferecer contribuições prático-conceituais à busca pela operacionalização da sustentabilidade nas organizações, por meio do fornecimento de informações para a eliminação de fragilidades e para a sugestão de avanços.

Metodologicamente, a presente pesquisa caracteriza-se como qualitativa, teórica, exploratória $e$ bibliográfica (DEMO, 2000). O estudo inicia-se com uma revisão geral da literatura sobre o tema, seguido da apresentação dos modelos e, por fim, apresenta as fragilidades e avanços dos modelos destacados, bem como a análise dos modelos com base em um quadro de referência com condições ideais. O Quadro 1 elenca os principais temas e os pontos de análise contidos neste artigo.

\begin{tabular}{|c|c|}
\hline TEMA EM PERSPECTIVA & O QUE INVESTIGAR? \\
\hline $\begin{array}{c}\text { Sustentabilidade } \\
\text { Organizacional: } \\
\text { Levantamento Conceitual }\end{array}$ & $\begin{array}{c}\text { Fundamentações teóricas que } \\
\text { permitam uma compreensão } \\
\text { coerente } e \text { ideal do conceito de } \\
\text { sustentabilidade organizacional, } \\
\text { bem como de suas dimensões. }\end{array}$ \\
\hline $\begin{array}{c}\text { Gestão da Sustentabilidade } \\
\text { Organizacional: } \\
\text { Quadro-Referência de } \\
\text { Condições Ideais }\end{array}$ & $\begin{array}{c}\text { Condições ideais para a } \\
\text { gestão da sustentabilidade } \\
\text { em contexto organizacional. }\end{array}$ \\
\hline $\begin{array}{c}\text { Modelos de } \\
\text { operacionalização } \\
\text { da sustentabilidade } \\
\text { organizacional }\end{array}$ & $\begin{array}{c}\text { Identificação e apresentação } \\
\text { de modelos que propõem }\end{array}$ \\
\hline $\begin{array}{c}\text { Análise Comparativa } \\
\text { entre os modelos em } \\
\text { perspectiva e destes com } \\
\text { o framework proposto }\end{array}$ & $\begin{array}{c}\text { sustentabilidade organizacional. } \\
\text { frastiveis convergências, a }\end{array}$ \\
\hline
\end{tabular}

Quadro 1: Protocolo de coleta e análise de dados Fonte: Elaborado pelos autores deste artigo

Para o alcance de tal objetivo, o artigo é apresentado em cinco partes: introdução; levantamento conceitual da sustentabilidade organizacional; proposição de um quadro-referência com condições ideais para a gestão da sustentabilidade em contexto organizacional; modelos de operacionalização da sustentabilidade organizacional; análise sobre os modelos apresentados; e considerações finais.

\section{Sustentabilidade Organizacional (SO): LEVANTAMENTO CONCEITUAL}

Desde a década de 1990, quando o desenvolvimento sustentável atingiu maior repercussão tanto no âmbito dos debates acadêmicos, quanto no cenário empresarial, inúmeros conceitos são propostos para se fazer menção a processos de gestão voltados ao alcance da sustentabilidade. Designações frequentemente utilizadas incluem: desenvolvimento sustentável, sociedades sustentáveis, crescimento sustentável, sustentabilidade estratégica, sustentabilidade corporativa e sustentabilidade organizacional; cada uso tem seu próprio significado, colocando uma ênfase pequena em um ou outro aspecto do conceito (VAN MARREWIJK, 2003; HAHN; SCHEEMESSER, 2006; VOS, 2007). Com vistas à padronização das designações, utilizar-se-á neste artigo a denominação Sustentabilidade Organizacional (SO).

Segundo Cheng, Fet e Holmen (2010), a sustentabilidade nas organizações pode ser considerada sob duas perspectivas: uma é macro e a outra é micro. Sob a perspectiva macro, a SO é vista como uma maneira de mobilizar o setor empresarial para contribuir com o desenvolvimento sustentável. Já por uma visão micro, implementar a SO refere-se à construção de uma plataforma de aprendizado na qual a organização possa difundir visões econômicas, sociais e ambientais do nível estratégico para o operacional, ao mesmo tempo em que seja capaz de agregar conhecimentos.

Van Marrewijk e Werre (2003) afirmam que a SO refere-se às atividades da empresa que demonstram a inclusão de aspectos sociais e ambientais às suas operações econômicas e interações com stakeholders. Para Dyllick e Hockerts (2002), a SO pode ser definida como o encontro das necessidades de stakeholders (funcionários, clientes, comunidades, grupos de pressão) sem que a capacidade de sustentar necessidades futuras seja comprometida. Conforme o entendimento de Smith e Sharicz (2011), a SO é o resultado das atividades de uma organização, voluntárias ou regidas por leis, que demonstram a habilidade dela em manter viáveis suas operações, incluindo a viabilidade financeira, enquanto não impacta negativamente os sistemas social e ambiental.

A partir da exposição de essas poucas conceituações, em relação a tantas outras encontradas na 
literatura, já é possível perceber a grande variação de designações e a ausência de uma definição singular ou consensual para a sustentabilidade organizacional. Tal circunstância deixa margem para considerar que o conceito de SO, por ser ainda muito amplo e até mesmo vago, deve ser substituído por definições mais específicas de forma equivalente aos níveis de desenvolvimento, consciência e ambição das organizações. Há o entendimento de que cada organização possa optar pela abordagem de SO que seja mais coerente com seus objetivos, propósitos e estratégias, bem como mais apropriada às circunstâncias sociais nas quais atua $e$ aos valores dominantes que a configura (VAN MARREWIJK; WERRE, 2003). Vos (2007), ao deliberar acerca de uma definição da sustentabilidade em contexto específico, argumenta que conceituações influentes da sustentabilidade devem desfrutar de consenso, em nível organizacional, comunitário e social.

Dessas discussões, concorda-se com van Marrewijk e Werre (2003) e Vos (2007) em relação à essencialidade do contexto ao se tratar de sustentabilidade nas organizações. O fator contextual possibilita às organizações atuar de forma alinhada aos objetivos da sustentabilidade, conforme a sua realidade de contexto, tanto interna quanto externa. Entretanto, agir conforme o contexto não implica que para cada organização deva existir um conceito e um modelo de gestão específicos. Admoesta-se que um framework global de gestão sistêmica e estrutural para administrar a sustentabilidade organizacional seja necessário a fim de possibilitar a definição de parâmetros e comparações em diversos níveis, inter ou intraorganizações. A contextualização é orientada para os casos de peculiaridades de cada organização, permanentes ou temporários, que afetem a gestão da sustentabilidade.

Da mesma forma que a conceituação da sustentabilidade se apresenta como um desafio para as organizações, a tradução do conceito na prática organizacional também o é. Dentre as inúmeras tentativas de operacionalizar a SO, destaca-se a contribuição de Elkington (1999), cujo trabalho demonstra o relacionamento entre os três pilares da sustentabilidade (social, econômico e ambiental), conhecidos na literatura como Triple Bottom Line - TBL, uma perspectiva de análise da sustentabilidade cada vez mais aceita pela sociedade e pelas organizações. Conforme as afirmações de Dyllick e Hockerts (2002), adeptos a este modelo, os três pilares possuem diferentes propriedades e, por isso, requerem diferentes abordagens.

À luz do TBL, para atingir a sustentabilidade, as empresas devem alavancar seus capitais econômico, social e ambiental - pilares estes inter-relacionados e que se influenciam mutuamente - enquanto contribuem para o desenvolvimento sustentável em seu domínio político. A partir da constatação de que as ações organizacionais não devem ser consideras sustentáveis quando atenderem, ainda que eficientemente, apenas um ou outro pilar da sustentabilidade, emerge a necessidade de integrá-los. O próprio conceito de sustentabilidade organizacional proposto pelo TBL já prevê a integração (ELKINGTON, 1999; DYLLICK; HOCKERTS, 2002; LORENZETTI; CRUZ; RICIOLI, 2008; BARBIERI et al., 2010; CALLADO, 2010).

Diversos autores, tais como Dyllick e Hockerts (2002), Jamalli (2006), Callado (2010) e Dias et al. (2011), convencionaram converter os três pilares da sustentabilidade organizacional em três sustentabilidades: organizacional econômica, organizacional ambiental e organizacional social. As três sustentabilidades, conforme Dias et al. (2011), tornam-se então sustentadoras e viabilizadoras da sustentabilidade organizacional, logo, para alcançar o estado de sustentabilidade uma organização deve antes desenvolver suas sustentabilidades econômica, ambiental e social, de maneira equilibrada e conforme o contexto da organização.

Apresentadas as considerações conceituais sobre a SO, a seguir, será descrito um quadro de referência a fim de entender algumas condições ideais para a avaliação dos modelos para a gestão da SO, os quais serão apresentados e analisados na sequência.

\section{A Construção de um Quadro- -Referência para Gestão da Sustentabilidade Organizacional}

Tendo em vista a tendência de incorporação da sustentabilidade na gestão das organizações, acredita-se que o desenvolvimento de um quadro referência de condições ideias para tal possa auxiliar no esclarecimento de informações com vistas a fornecer contribuições prático-conceituais à busca pela operacionalização da sustentabilidade nas organizações. Dessa monta, serão desenvolvidas três premissas as quais representam condições ideais de gestão da sustentabilidade organizacional. 
É importante ressaltar que tais premissas representam de forma genérica as condições básicas para incorporar a gestão da sustentabilidade nas organizações e que estas premissas ou condições ideais foram definidas a partir da leitura, principalmente, dos próprios artigos desenvolvedores dos modelos analisados neste artigo. Por entender que os artigos que originaram os modelos aqui avaliados possuem representatividade internacional e que são abrangentes, pois propõem desde mudanças operacionais até culturais; acredita-se que as condições ideais levantadas neste tópico, abrangem as dimensões pertinentes para a aplicação de modelos de gestão da sustentabilidade e, posteriormente, uma avaliação e comparação dos modelos aqui elencados.

Contudo, de acordo com Searcy (2012), é importante enfatizar que a SO é um problema fundamentalmente complexo. As organizações são confrontadas com diferentes demandas dos stakeholders em constante mudança de prioridades, e uma infinidade de alternativas para enfrentar os desafios da sustentabilidade. Em reconhecimento a esta realidade, as empresas devem desenvolver estratégias para a sustentabilidade que sejam adequadas aos seus contextos locais e podem utilizar as condições ideais aqui desenvolvidas para esta tarefa. No entanto, para avaliar o sucesso ou o fracasso de iniciativas de sustentabilidade, ou seja, se são notados progressos em objetivos econômicos, ambientais e sociais fundamentais, um conjunto de indicadores deve ser utilizado, porém, este não é o foco do artigo.

Portanto, com respeito à primeira condição ideal de gestão da sustentabilidade nas organizações, na concepção de Azapagic (2003), um sistema de gestão da sustentabilidade organizacional deve emergir, ser incorporado e alinhado à visão e estratégia de negócios. A SO não deve ser considerada uma 'adição', muito além disso, ela precisa ser parte integral dos negócios em seu contexto, concebida como uma ferramenta 'guarda-chuva', o que envolve entender e agir concernente as questões chave da sustentabilidade. A implementação da SO significa, portanto, torná-la real na estratégia e operações (CHENG; FET; HOLMEN, 2010).

De acordo com Epstein (2008), para implementar uma estratégia de sustentabilidade eficaz é fundamental que os gestores compreendam as relações causais entre as várias ações que podem ser tomadas, além de integrar a sustentabilidade em decisões operacionais, táticas e estratégicas. É fundamental também que se reconheça que a estratégia, a liderança e processos de implementação são componentes essenciais para a gestão da sustentabilidade.

Acrescenta-se que esta implantação da sustentabilidade deve ocorrer de forma que os novos modos de operação tornem-se profundamente enraizados na organização. Adequações na estrutura organizacional incluem rotinas e processos de trabalho associados à entrega de valor aos clientes e outros stakeholders, tomadas de decisão, comunicação e processos diretivos com vistas a manter as várias partes da organização alinhada às estratégias e aos propósitos da $\mathrm{SO}$ (MOHRMAN; WORLEY, 2010). Do mesmo modo, é necessária uma mudança cultural, ou seja, a SO precisa ser sistematicamente integrada a todas as atividades organizacionais (AZAPAGIC; 2003).

Para complementar, em um framework para integrar o gerenciamento da qualidade e sustentabilidade Asif et al. (2011) entendem que para a gestão e implementação da SO é imprescindível que haja uma integração de estruturas e funções com estratégias prioritárias e atividades operacionais. Por meio de tais considerações, tem-se que uma primeira condição ideal para a gestão da sustentabilidade nas organizações é que a SO deve ser implementada como parte integral e contextual dos negócios por meio de sua inserção em decisões operacionais, táticas e estratégicas.

A incorporação da $\mathrm{SO}$ em decisões operacionais, táticas e estratégicas, portanto, implica o aprendizado e o desenvolvimento de capacidades de ordem superior (CHENG; FET; HOLMEN, 2010), as quais podem ser entendidas como competências que, segundo Munck, Munck e Borim-de-Souza (2011), remetem à capacidade organizacional de conceder retorno econômico suficiente e agregar valor social aos indivíduos sem comprometer o ambiente. Para Valente (2012), a orientação das organizações para a sustentabilidade define-se por meio de uma abordagem colaborativa e coordenada que prevê a mobilização de competências de diversos stakeholders, internos e externos, operando como um sistema unificado. Portanto, por entender a sustentabilidade como uma competência organizacional, e esta como instrumento de implementação $e$ mensuração/acompanhamento, faz com que se utilize de forma articulada os recursos organizacionais frente aos objetivos estratégicos. 
Ademais, outra característica tida como importante para a avaliação de modelos para a sustentabilidade é a questão de que investimentos nos ativos social, financeiro $e$ ambiental precisam ser simultâneos $e$ coordenados (MUNCK; MUNCK; BORIM-DE-SOUZA 2011; WHEELER et al., 2005). Segundo Elkington (1999), o idealizador da abordagem do TBLé imprescindível que haja uma operacionalização simultânea e integrativa entre estas três dimensões na atuação organizacional. De fato, a principal evidência deste modelo é a de que a organização não deve basear suas decisões em apenas um dos pilares, uma vez que tal fato pode acarretar o insucesso de qualquer estratégia organizacional de longo prazo e, por conseguinte, prejuízos econômicos, sociais e ambientais (LAVILLE, 2009; MUNCK; MUNCK; BORIM-DE-SOUZA, 2011).

Asif et al. (2011) assumem que desenvolver mecanismos de governança com controles gerenciais para promover a institucionalização do modelo implementado, bem como o desenvolvimento de competências são essenciais para a integração entre gestão e sustentabilidade. Neste contexto, uma segunda condição ideal para a gestão da sustentabilidade nas organizações é a admoestação que a SO necessite pautar-se pelo desenvolvimento de competências que orientem a implementação e mensuração/acompanhamento que remetam para retornos econômicos, agregação de valor social e preservação ambiental. Sendo que os três elementos sejam atingidos concomitantemente considerando trade-offs.

A sustentabilidade deve, portanto, representar um novo modo de agir da organização, e não apenas incidir sobre práticas voluntárias e respostas às exigências dos stakeholders (VALENTE, 2012). Isso significa, primordialmente, que os investimentos em sustentabilidade precisam proporcionar respostas efetivas para além das exigências legais (MOLTENI; PEDRINI, 2010). Nesse contexto, Asif et al. (2011) acreditam que, para a gestão da sustentabilidade obter os resultados pertinentes aos seus objetivos é necessária uma realocação de recursos e que os princípios da SO sejam sociabilizados para desenvolver uma interpretação compartilhada e alcançar os resultados almejados. Enfim, como terceira e última condição ideal da gestão da sustentabilidade organizacional, entende-seque a gestão da SO deve proporcionar respostas além das exigências legais que contribuam para a competitividade, lucratividade e para o sucesso das políticas consideradas sustentáveis no longo prazo.

Em síntese das condições ideais apresentadas, o quadro referência foi desenvolvido, visualizado no Quadro 2:

\begin{tabular}{|c|c|c|}
\hline \multicolumn{2}{|r|}{ PARÂMETROS } & \multirow[b]{2}{*}{\begin{tabular}{l}
\multicolumn{1}{c}{ REFERÊNCIAS } \\
Azapagic (2003); \\
Epstein (2008); \\
Cheng, Fet e \\
Holmen, (2010); \\
Mohrman e Worley (2010) \\
Munck, Munck e Borim- \\
de-Souza (2011)
\end{tabular}} \\
\hline 1 & $\begin{array}{l}\text { A SO deve ser implementada } \\
\text { como parte integral e } \\
\text { contextual dos negócios } \\
\text { por meio de sua inserção } \\
\text { em decisões operacionais, } \\
\text { táticas e estratégicas. }\end{array}$ & \\
\hline 2 & $\begin{array}{l}\text { A SO deve se pautar } \\
\text { pelo desenvolvimento } \\
\text { de competências que } \\
\text { orientem a implementação } \\
\text { e mensuração/ } \\
\text { acompanhamento que } \\
\text { remetam para retornos } \\
\text { econômicos, agregação de } \\
\text { valor social e preservação } \\
\text { ambiental. Sendo que } \\
\text { os três elementos sejam } \\
\text { atingidos concomitantemente } \\
\text { considerando trade-offs. }\end{array}$ & $\begin{array}{l}\text { Elkington (1999); } \\
\text { Wheeler et. al (2005); } \\
\text { Laville (2009); } \\
\text { Cheng, Fet e } \\
\text { Holmen, (2010); } \\
\text { Munck, Munck e Borim- } \\
\text { de-Souza (2011); } \\
\text { Valente (2012) }\end{array}$ \\
\hline 3 & $\begin{array}{l}\text { A gestão da SO deve } \\
\text { proporcionar respostas } \\
\text { além das exigências } \\
\text { legais que contribuam } \\
\text { para a competitividade, } \\
\text { lucratividade e para o } \\
\text { sucesso das políticas } \\
\text { consideradas sustentáveis } \\
\text { no longo prazo. }\end{array}$ & $\begin{array}{l}\text { Azapagic (2003); } \\
\text { Molteni e Pedrini (2010); } \\
\text { Valente (2012) }\end{array}$ \\
\hline
\end{tabular}

Quadro 2: Quadro referência das condições ideias para a avaliação de modelos de gestão da SO

Fonte: Elaborado pelos autores deste artigo

A partir dessas considerações, serão apresentados, a seguir, os modelos de operacionalização da sustentabilidade que serão objeto de estudo comparativo entre eles e com este quadro referência, o que gerará discussões em torno de avanços e fragilidades desses modelos.

\section{Modelos de Operacionalização da Sustentabilidade nas Organizações}

Stubbs e Cocklin (2008) frisam que embora haja um vasto campo de publicações na literatura científica acerca da sustentabilidade, a compreensão deste fenômeno para o meio empresarial, assim como 
a ocorrência de sua operacionalização por meio de modelos de gestão ainda não se apresentam de forma significativa. Como salientado na introdução deste artigo, são poucos os estudos que buscam desenvolver e/ou aplicar algum tipo de modelo de gestão da sustentabilidade e, em geral, os que o fazem frequentemente não possuem originalidade, limitando-se apenas a reproduzirem repetições.

Com a intenção de identificar avanços e também analisar fragilidades com base em referências conceituais adotados como ideais, foram selecionados cinco modelos que buscam a operacionalização da sustentabilidade nas organizações, desenvolvidos em várias localidades e anos diferentes. O Quadro 3 elenca a nomenclatura dos modelos analisados, seus respectivos autores e a sua origem. Na sequência, dá-se início às descrições de cada modelo.

\begin{tabular}{|c|c|c|}
\hline $\begin{array}{l}\text { Modelos de Gestão dA } \\
\text { Sustentabilidade }\end{array}$ & Autores/ReFERÊNCIA & Origem \\
\hline $\begin{array}{c}\text { Sistema de gestão } \\
\text { da sustentabilidade } \\
\text { organizacional SGSO }\end{array}$ & Azapagic (2003) & Inglaterra \\
\hline $\begin{array}{l}\text { Rede Corporativa } \\
\text { Sustentável Local }\end{array}$ & Wheeler et. al (2005) & Inglaterra \\
\hline $\begin{array}{c}\text { Balanced Scorecard } \\
\text { Hexagonal - BSH } \\
\text {-Framework conceitual de } \\
\text { uma abordagem integrada } \\
\text { para a sustentabilidade } \\
\text { organizacional }\end{array}$ & $\begin{array}{l}\text { Cheng, Fet e } \\
\text { Holmen (2010) }\end{array}$ & Noruega \\
\hline $\begin{array}{c}\text { Síntese Socioeconômica } \\
\text { - SSE }\end{array}$ & $\begin{array}{l}\text { Molteni e Pedrini } \\
\text { (2010) }\end{array}$ & Itália \\
\hline $\begin{array}{c}\text { Framework Representativo } \\
\text { do Acontecimento } \\
\text { da Sustentabilidade } \\
\text { Organizacional FRASOR }\end{array}$ & $\begin{array}{l}\text { Munck, Munck } \\
\text { e Borim-de- } \\
\text { Souza (2011) }\end{array}$ & Brasil \\
\hline
\end{tabular}

Quadro 3: Modelos de gestão da sustentabilidade em análise Fonte: Elaborado pelos autores deste artigo

\subsection{Sistema de Gestão da Sustentabilidade Corporativa (SGSO)}

O primeiro modelo apresentado é desenvolvido por Azapagic (2003). O autor acredita que alcançar a sustentabilidade organizacional, pautada no desenvolvimento das dimensões econômica, social e ambiental que impactam e são impactadas pela empresa, não é uma tarefa trivial, envolve visão, comprometimento $e$ liderança. Bem por isso há a necessidade de facilitar a convergência e a padronização de abordagens para a sua gestão, demonstrada por meio de um framework, apresentado na Figura 1. Segundo o autor, uma abordagem integrativa de gestão da SO pode alavancar inúmeras oportunidades para aprimorar a competitividade proporcionando soluções de valor agregado, $e$ potencializar a reputação empresarial.

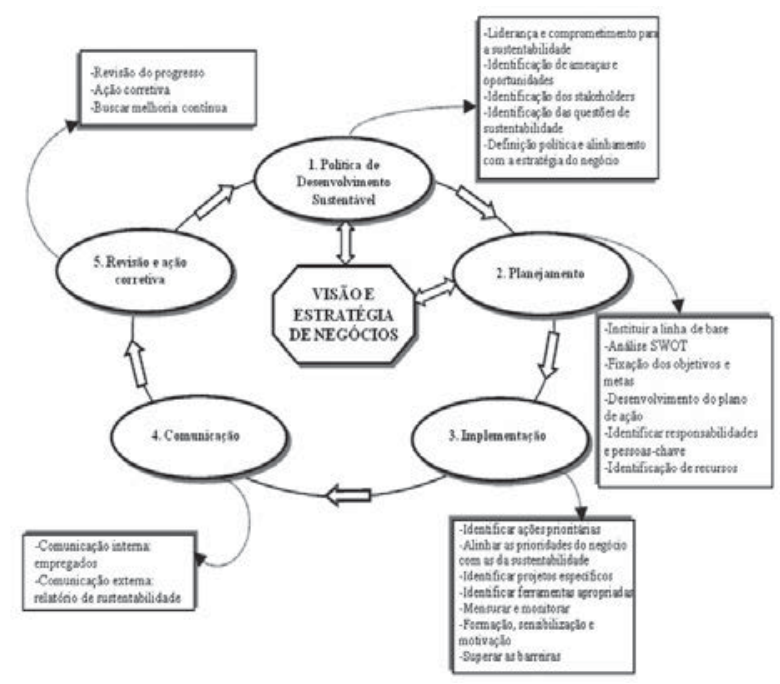

Figura 1: Sistema de gestão da sustentabilidade organizacional Fonte: Azapagic (2003, p. 305, tradução nossa)

Conforme observado na Figura 1, o sistema de gestão da sustentabilidade organizacional emerge e é incorporado dentro da visão e estratégia de negócios. É preciso conceber a sustentabilidade como uma ferramenta 'guarda-chuva' que auxilia na identificação e gerenciamento dos riscos econômicos, ambientais e sociais de maneira integrada. O framework proposto por Azapagic (2003) compreende cinco estágios interligados.

$\mathrm{O}$ primeiro passo, relacionado diretamente à visão e estratégia de negócios, refere-se à política de desenvolvimento sustentável, a qual envolve a demonstração de liderança e do comprometimento com a sustentabilidade, a identificação de ameaças e de oportunidades, dos stakeholders e também das questões de sustentabilidade - social, econômica e ambiental. Deve haver ainda a definição política e alinhamento com a estratégia e visão do negócio. A segunda etapa do sistema de gestão da SO é o planejamento, no qual são necessárias a realização de uma análise SWOT da sustentabilidade e a definição de objetivos e metas para o desenvolvimento de um plano de ação. 
No planejamento há a identificação do quadro de pessoal necessário e atribuição de responsabilidades, além da especificação e alocação de recursos.

No terceiro passo ocorre a implementação do sistema de gestão da SO a qual inclui mudanças na cultura organizacional e nas atitudes dos empregados, principalmente por meio de treinamentos e desenvolvimento de competências. Nesta fase iniciam-se as ações prioritárias para se alcançar a sustentabilidade de forma a alinhar as prioridades da sustentabilidade com as prioridades da organização. A identificação de ferramentas apropriadas é importante neste estágio, porque podem ser usadas para ajudar na implementação da estratégia de sustentabilidade. Fazem-se necessários a mensuração e monitoramento, bem como a sensibilização, formação e motivação de todos os envolvidos. O quarto passo concerne à comunicação organizacional, tanto em âmbito interno quanto externo. O progresso do sistema precisa ser comunicado para todos os empregados periodicamente, uma vez que precisam estar conscientes e ter acesso aos relatórios anuais de sustentabilidade produzidos. Já a comunicação externa contribui para manter a transparência e para responder a questões emergentes e pressões.

Por fim, o quinto e último passo se refere à revisão e ação corretiva. Neste estágio, faz-se uma revisão a fim de observar se os objetivos e metas foram alcançados. Caso não tenham sido alcançados, os motivos de tal ocorrência precisam ser claramente identificados $e$ ações corretivas apropriadas devem ser tomadas. Por outro lado, se os objetivos forem atingidos e comunicados claramente, o processo começa novamente com a revisão e o realinhamento da política com as estratégias do negócio (AZAPAGIC, 2003).

Na concepção de Azapagic (2003), desenvolver a sustentabilidade organizacional exige uma mudança de longo prazo e em diversos níveis, por meio do pensamento estratégico e de um sistema de abordagem. A SO não é uma 'adição', precisa ser parte integral dos negócios e, como todas outras atividades organizacionais, demanda uma gestão apropriada. O autor ressalta que nenhum sistema ou modelo de gestão da sustentabilidade é capaz de tornar o negócio sustentável caso não haja um real comprometimento da alta cúpula da organização.

\subsection{Rede Corporativa Sustentável Local (SLEN - sigla em inglês)}

Segundo Wheeler et al. (2005), o modelo SLEN tem por finalidade descrever a maneira pela qual iniciativas sustentáveis em países em desenvolvimento podem prosperar em ambientes de redes baseados na confiança.

Os autores examinaram 50 estudos de caso de empresas aparentemente bem-sucedidas, autossuficientes e sustentáveis, com atividades baseadas nos países em desenvolvimento. O estudo mostrou que as empresas estão inseridas em densas redes entre organizações privadas; comunidades locais; organizações sem fins lucrativos; entre outros atores, nas quais as atividades são autogeridas de forma que criem valor em termos econômicos, sociais, humanos e ecológicos. Cinco importantes tópicos foram definidos como características dos atores inseridos no modelo SLEN: âncora financeira; missão social ostensiva; resultados sustentáveis; investimento exógeno; e objetivos variados dos participantes.

A identificação de uma âncora financeira nas redes é importante para o desenvolvimento do modelo SLEN à medida que permite assegurar sua sustentabilidade financeira. Ainda que de portes distintos (micro, pequenas, médias empresas ou multinacionais), empresas com missões sociais ostensivas são, com frequência, uma parte integral das redes. As redes fornecem uma oportunidade para empresas, comunidades, indivíduos, governos, agências desenvolvimentistas e ONGs a reconhecer uma base de ativos compartilhados e construir um ciclo virtuoso de ativos crescentes e resultados sustentáveis. Estes últimos estão classificados em quatro categorias: (1) lucros e retornos seguros em investimentos; (2) desenvolvimento econômico local e comercial; (3) aumento da qualidade de vida humana e ecológica; e (4) independência econômica individual e comunitária.

O investimento exógeno é construído a partir de ativos já existentes também em quatro categorias: capital humano, capital social, capital financeiro e capital ecológico. Estas categorias não são exatamente necessárias para a expansão da rede, mas estão presentes de alguma forma. O reabastecimento de 
recursos ou o reinvestimento deve ocorrer para que a rede cresça e se torne independente. No modelo SLEN todos participantes concordam com o primeiro propósito da rede: a colaboração. Isto faz com que existam poucas agendas normativas $e$, consequentemente, não se oprima os participantes a nenhum constrangimento ideológico. $\mathrm{O}$ valor e os resultados obtidos por meio da rede diferem para cada participante conforme o que for considerado mais importante para ele. A Figura 2 representa o modelo.

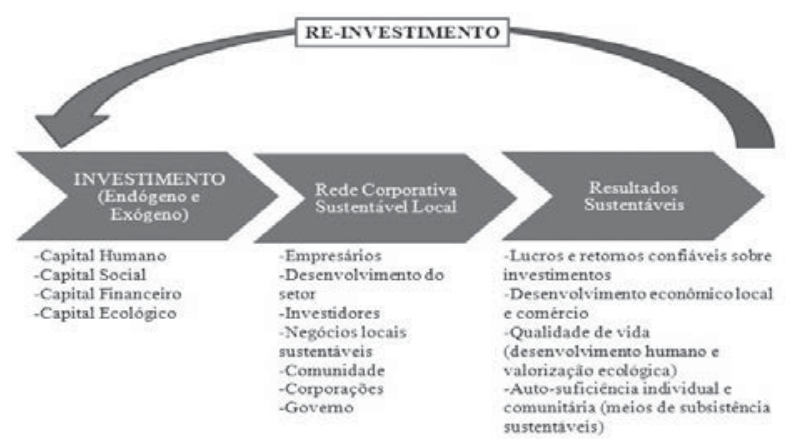

Figura 2: O modelo de Redes Corporativas Sustentáveis Locais (SLEN)

Fonte: Wheeler et al. (2005, p. 39 tradução nossa)

De modo geral, investimentos nos ativos humano, social, financeiro e ecológico precisam ser simultâneos e coordenados a fim de maximizar o impacto da formação de SLENs. Para tanto, serão necessários altos níveis de cooperação entre agências internacionais, governos, empresas multinacionais, grandes empresas nacionais em países em desenvolvimento, entre outros. Wheeler et al. (2005) salientam que estes atores deverão pensar em si mesmos para além de suas funções políticas, como construtores de redes, construtores de capacitação, incubadores de rede e inovadores, líderes e disseminadores de aprendizados.

\subsection{Framework Balanced Scorecard Hexagonal (BSH)}

O terceiro modelo de sustentabilidade organizacional a ser apresentado é descrito por Cheng, Fet e Holmen (2010). As autoras identificam que como alicerces para um quadro integrado de Sustentabili- dade Corporativa deve-se usar o Balanced Scorecard (BSC) e o Mapa Estratégico. No modelo elaborado por Cheng, Fet e Holmen (2010), o conceito do BSC foi estendido em um fluxo integrado de mecanismos que direcionam a transposição das visões econômica, social e ambiental do nível estratégico para o operacional simultaneamente à agregação de aprendizados que emergem dessas visões em nível operacional, facilitando, assim, a captura de planejamentos estratégicos a partir da estratégia realizada no cotidiano.

Com foco específico na representação visual do hexágono (Figura 3), a sua metade inferior representa os ativos intangíveis da empresa. O ciclo é iniciado na parte inferior direita com a perspectiva 'Aprendizagem e Crescimento' com foco nos funcionários, suas habilidades e conhecimentos, por meio de treinamentos e desenvolvimento de competências. No sentido horário, a perspectiva de aprendizado $e$ crescimento leva à perspectiva 'Processos Internos', centrada na qualidade e produtividade dos processos internos da empresa. A conexão lógica seguinte é a perspectiva 'Cliente', que focaliza clientes diretos $e$ consumidores finais, e o oferecimento de valor único.

A próxima conexão ocorre na metade superior do hexágono, a qual delineia a abordagem do 'triple bottom line'. A perspectiva 'Ambiental' possui a conexão lógica com a perspectiva 'Clientes' devido ao pressuposto de que os produtos e processos são desenvolvidos em consideração ao desempenho ambiental da organização. Já a perspectiva 'Financeira' é orientada tanto pela perspectiva 'Ambiental' quanto 'Social', com vistas a lembrar os gestores de que os processos e conteúdos estratégicos devem envolver ambas estas perspectivas, sem perder de vista o desempenho econômico. Por fim, a perspectiva 'Social' é orientada em sentido anti-horário pela perspectiva 'Aprendizado e Conhecimento', e possui foco no planejamento estratégico em termos de transformar problemas sociais emergentes tanto da comunidade local quanto da sociedade em geral.

A partir dessas seis perspectivas, é elaborada a abordagem de Balanced Scorecard Hexagonal integrada para a sustentabilidade organizacional, composta por quatro subsistemas, como mostra a Figura 3. 


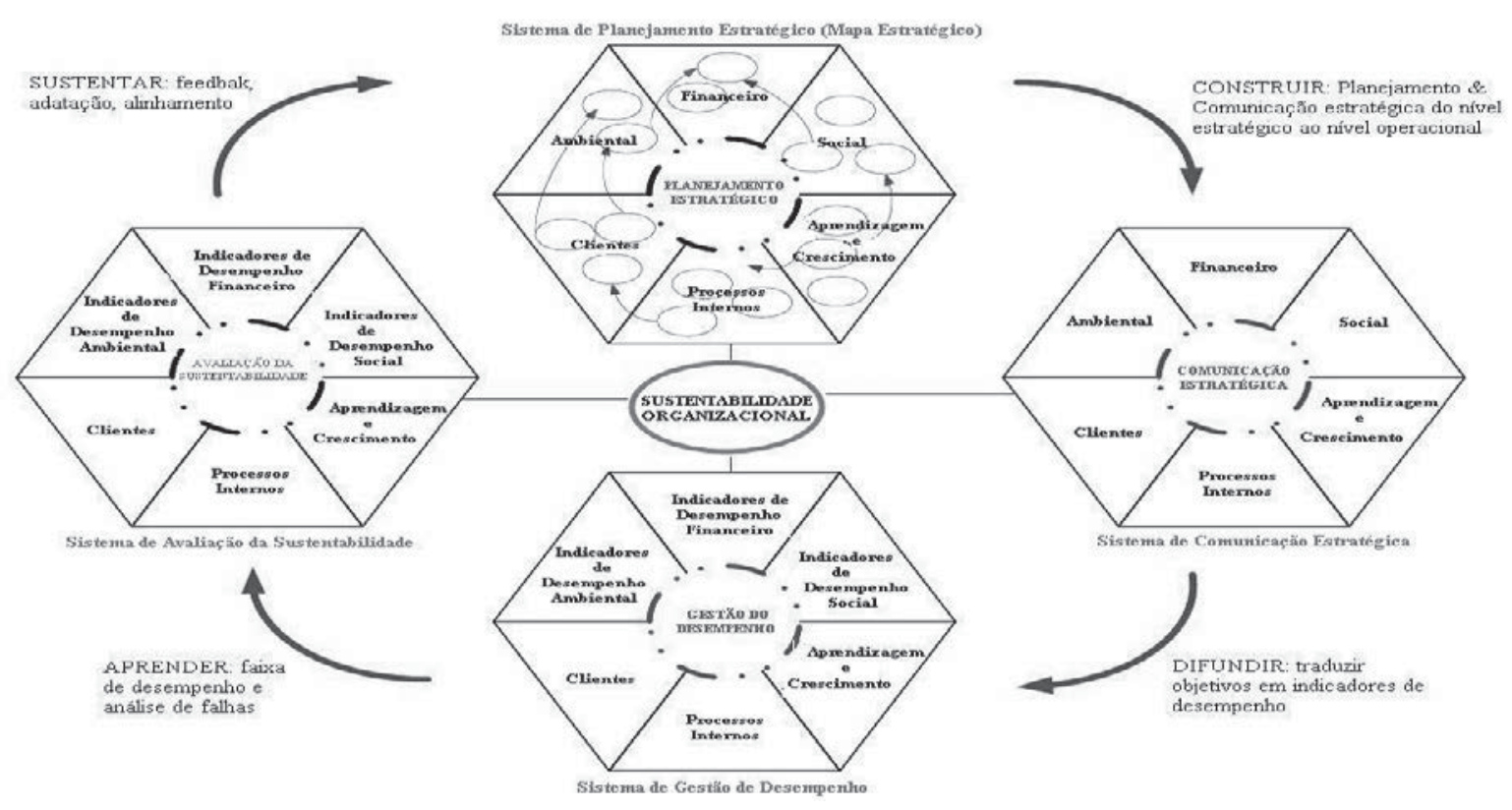

Figura 3: Framework Balanced Scorecard Hexagonal (BSH)

Fonte: Cheng, Fet e Holmen (2010, p. 10 tradução nossa)

O ciclo estratégico de sistema de gestão representado pelo framework da Figura 3 é iniciado pelo 'Sistema de Planejamento Estratégico', onde é permitido à organização construir uma plataforma de aprendizagem, a fim de efetivamente utilizar o meio ambiente e a sociedade como direcionadores de recursos e de desenvolvimento de capacidades. Com objetivos estratégicos formulados, a organização precisará difundi-los pelas seis perspectivas a partir da comunicação vertical e horizontal em cada unidade de negócio, por meio do 'Sistema de Comunicação Estratégica'. Passando para o 'Sistema de Gestão do Desempenho', as definições de objetivos para cada unidade de negócio são traduzidas em indicadores de desempenho específicos, a fim de integrar as unidades de sistema na organização. As lacunas entre os desempenhos planejado e ocorrido são identificados para permitir que a organização aprenda e seja aprimorada. No término do ciclo está o 'Sistema de Avaliação da Sustentabilidade' em que dados sobre desempenho e falhas na organização são designados em indicadores de desempenho interno e externo. A organização então adapta sua estratégia e realinha seus recursos a fim de sustentar seu desempenho.
No contexto do framework, os objetivos estratégicos são desenvolvidos em nível localizado, unidade de negócios e nível individual para facilitar a coordenação e cooperação entre eles. Assim, a comunicação estratégica e o aprendizado são a espinha dorsal do framework Balanced Scorecard Hexagonal. Por fim, a implementação da SO significa torná-la real na estratégia e operações. Ao mesmo tempo, a execução também implica o aprendizado e o desenvolvimento de capacidades de ordem superior (CHENG; FET; HOLMEN, 2010).

\subsection{Síntese Socioeconômica}

O quarto modelo de proposição da operacionalização da sustentabilidade organizacional é o desenvolvido por Molteni e Pedrini (2010). A Síntese Socioeconômica compreende soluções práticas que combinam alta competitividade e desempenho econômico com ótimos desempenhos sociais e ambientais. Por esta síntese, os autores entendem novas soluções que proporcionem respostas efetivas a expectativas de grupos de stakeholders, para além das exigências legais, que contribuam para o aumento da competitividade, lucratividade e para o sucesso no longo prazo da organização. A Figura 4 ilustra este modelo. 


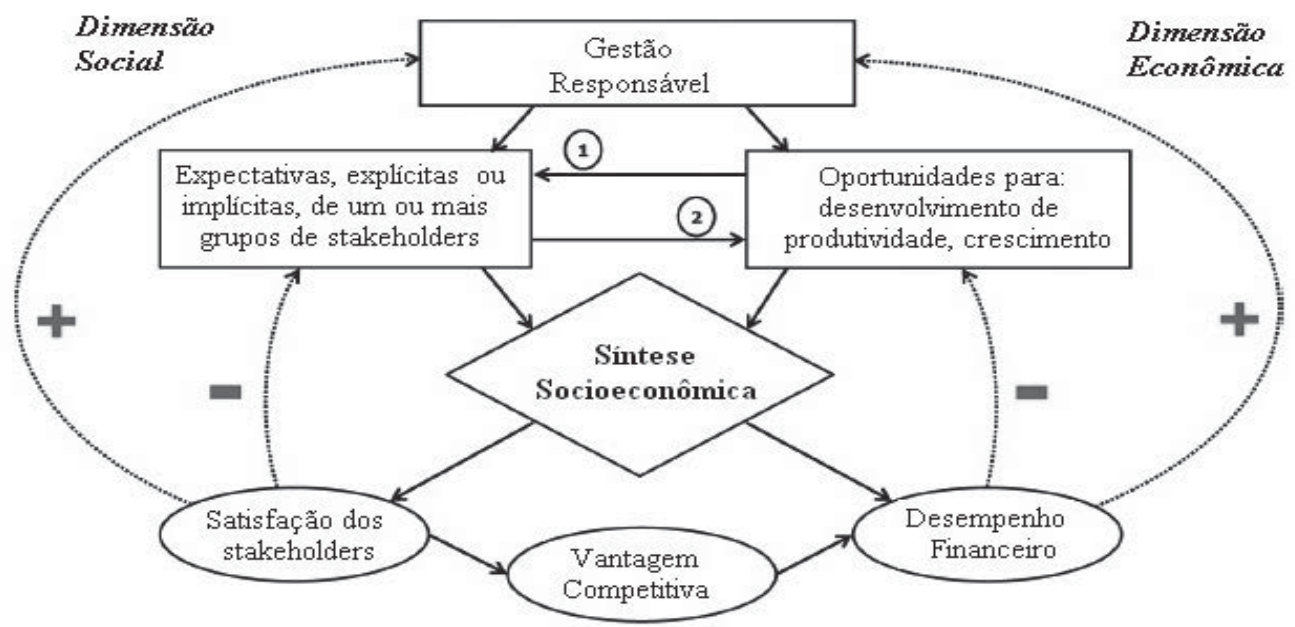

Figura 4: Síntese socioeconômica

Fonte: Molteni e Pedrini (2010, p. 628 tradução nossa)

Molteni e Pedrini (2010) chamam a atenção para os efeitos de feedback presentes na síntese socioeconômica, que a equilibra e a reforça. Há dois processos de equilíbrio, dado que a vantagem competitiva alcançada auxilia a aproximar possíveis lacunas entre estratégia planejada e estratégia realizada, bem como em relação à satisfação de stakeholders. Este efeito de equilíbrio explica por que a síntese socioeconômica tende a perder o seu valor ao longo do tempo dos pontos de vista competitivo e social, tornando-se uma mera condição de trabalho da empresa. Assim, há a necessidade de contínuos re-lançamentos, novos projetos com suas próprias características socioeconômicas. Há também dois processos de reforço, visto que melhores resultados econômicos aumentam a disponibilidade de recursos financeiros. Portanto, ambos os processos de equilíbrio e de reforço alimentam o desenvolvimento da organização e aumentam a vontade de satisfazer as necessidades dos stakeholders de maneiras diferentes.

Na concepção de Molteni e Pedrini (2010), a síntese socioeconômica concerne a uma vasta gama de elementos organizacionais, desde processos únicos até orientações estratégicas. Os autores fornecem uma classificação das soluções promovidas pela síntese socioeconômica, com sete níveis crescentes, como no Quadro 4. Nos níveis mais baixos, as soluções são de caráter genérico, sendo aplicáveis em diversas organizações e decididas por níveis gerenciais medianos, já nos níveis mais altos, as soluções oferecidas são mais específicas, decididas por níveis gerenciais de alta cúpula.

\begin{tabular}{|c|c|}
\hline $\begin{array}{c}\text { Nível } 1 \\
\text { Microações: }\end{array}$ & $\begin{array}{l}\text { Gestores são capazes de combinar } \\
\text { impactos positivos sociais ou ambientais } \\
\text { com benefícios econômicos. Ex: } \\
\text { adoção de lâmpadas frias e/ou uso } \\
\text { de sensores de aproximação. }\end{array}$ \\
\hline $\begin{array}{l}\text { Nível } 2 \text { - } \\
\text { Iniciativas } \\
\text { funcionais: }\end{array}$ & $\begin{array}{l}\text { Soluções inseridas na funcionalidade } \\
\text { organizacional que possuem um } \\
\text { amplo impacto nas microações. Ex: } \\
\text { introdução de enfermaria na empresa. }\end{array}$ \\
\hline $\begin{array}{l}\text { Nível } 3 \text { - } \\
\text { Iniciativas } \\
\text { transversais: }\end{array}$ & $\begin{array}{l}\text { Envolve mais funções e mais } \\
\text { negócios da empresa. Ex: política } \\
\text { global de economia de energia. }\end{array}$ \\
\hline $\begin{array}{l}\text { Nível } 4 \text { - } \\
\text { Estratégias } \\
\text { funcionais: }\end{array}$ & $\begin{array}{l}\text { Todas as atividades que pertencem a uma } \\
\text { função da empresa são interpretadas a } \\
\text { partir da dimensão socioambiental. Ex: } \\
\text { políticas de gestão de recursos humanos que } \\
\text { produzem benefícios para o funcionário e } \\
\text { para o desempenho financeiro da empresa. }\end{array}$ \\
\hline $\begin{array}{l}\text { Nível } 5 \text { - } \\
\text { Negócios } \\
\text { sociais e/ou } \\
\text { ambientais: }\end{array}$ & $\begin{array}{l}\text { Negócios em que impactos sociais e/ou } \\
\text { ambientais são centrais para a estratégia } \\
\text { competitiva da empresa. Ex: lançamento } \\
\text { de produtos que visam à satisfação de } \\
\text { necessidades de um grupo social fraco. }\end{array}$ \\
\hline $\begin{array}{l}\text { Nível } 6 \text { - Perfil } \\
\text { da empresa: }\end{array}$ & $\begin{array}{l}\text { Abordagem sinérgica entre o desempenho } \\
\text { econômico e resultados socioambientais } \\
\text { que inspira o perfil da organização. Ex: } \\
\text { dispersão da empresa em uma localidade } \\
\text { rural em detrimento de sua concentração. }\end{array}$ \\
\hline $\begin{array}{c}\text { Nível } 7 \text { - } \\
\text { Identidade } \\
\text { da empresa: }\end{array}$ & $\begin{array}{l}\text { A orientação social e/ou ambiental } \\
\text { constitui o ponto central da identidade } \\
\text { da empresa. Todas as decisões são } \\
\text { tomadas conforme este critério. }\end{array}$ \\
\hline
\end{tabular}

Quadro 4: Níveis das Soluções Promovidas pelaSíntese Socioeconômica

Fonte: Adaptado de Molteni e Pedrini (2010) 
Molteni e Pedrini (2010) advertem que quando a Síntese Socioeconômica ocorre em níveis mais baixos tende a ser mais facilmente imitada por diferentes organizações. Contrariamente, as soluções oferecidas pelos níveis mais altos da síntese socioeconômica apenas podem ser imitadas com muito mais dificuldade, em razão de sua especificidade. Na visão dos autores, o modelo da Síntese Socioeconômica pode ser utilizado em duas circunstâncias diferentes: para avaliar se um processo ou uma estratégia são realmente virtuosos e para estimular inovações designadas para o bem comum. Em suma, o modelo da Síntese Socioeconômica fornece orientação e auxílio aos gestores para a prática da sustentabilidade. Simultaneamente, este modelo demanda das pessoas a busca pelo bem comum e capacidades e criatividade suficientes para superar conflitos e encontrar novas soluções.

\subsection{Framework Representativo do Acontecimento da Sustentabilidade Organizacional (FRASOR)}

O quinto e último modelo apresentado é o elaborado por Munck, Munck e Borim-de-Souza (2011). Partindo da constatação da falta de um quadro teórico global e consolidado para a compreensão teórico-aplicada sobre a sustentabilidade organizacional e suas especificidades, os autores propuseram um framework representativo dos processos necessários ao acontecimento da SO. Os autores a assumem como um objetivo organizacional estratégico e, ao buscarem por uma teoria que permitisse contemplar um agir organizacional processual capaz de qualificar, categorizar e conduzir os preceitos da sustentabilidade em contexto organizacional, fizerem uso da abordagem teórica do Agir Organizacional (MAGGI, 2006) unida à lógica das competências (MILLS et al., 2002) e de ambas à abordagem integrativa do TBL (ELKINGTON, 1999).

A teoria do Agir Organizacional, de acordo com seu propositor Maggi (2006), é tanto uma teoria do agir social como uma teoria do agir racional. O agir social indica um agir do qual o sentido intencionado, de um ou mais sujeitos, se dirige ao agir de outros sujeitos. Assim sendo, o agir organizacional concerne tanto aos processos de ação de um sujeito singular quanto aos processos de ação coletiva. Conforme Munck, Munck e Borim-de-Souza (2011), visualiza-se que o agir organizacional é um macroprocesso consequente de inúmeros subprocessos, influenciado tanto por fatores externos quanto internos. Esses processos, para serem efetivamente realizados, precisam ser comprovadamente compreendidos pelos indivíduos que o realizarão $e$ deles participarão.

Depois de compreendidos os fundamentos da teoria do agir organizacional, fizeram uso da lógica das competências. Os autores definem a competência como um saber fazer coletivo de alta qualidade, que representa a operacionalização sistêmica dos recursos considerando os objetivos e estratégias organizacionais $e$ as influências ambientais. Acrescentam ainda que o agir organizacional pode ser traduzido como uma competência organizacional, permitindo objetividade na descrição e tornando-o capaz de registrar eficiência na ação organizativa frente aos resultados almejados. Segundo os autores

[...] competência, portanto, relata eficiência, ou seja, o melhor uso possível $e$ articulado dos recursos. É ela meio de fomento e verificação da eficácia nos processos de ações e decisões. (MUNCK; MUNCK; BORIM-DE-SOUZA, 2011, p. 152)

Por essa inferência, os autores ressaltam que o conceito de competência organizacional remete à capacidade organizacional de conceder retorno econômico suficiente e agregar valor social aos indivíduos, complementado com os preceitos do triple bottom line, agrega-se a exigência de não comprometer o meio ambiente. Com base nos preceitos do TBL, os autores propõem três competências chaves para o acontecimento da SO: Sustentabilidade Econômica, Sustentabilidade Ambiental e Sustentabilidade Social. Por seu turno, estas três sustentabilidades componentes da SO são compostas por três outras competências que as suportam: a ecoeficiência, a justiça socioambiental e a inserção socioeconômica. Quando validadas, as três competências de suporte permitem um equilíbrio organizacional sistêmico representante da conquista da sustentabilidade organizacional. Vide modelo na Figura 5. 


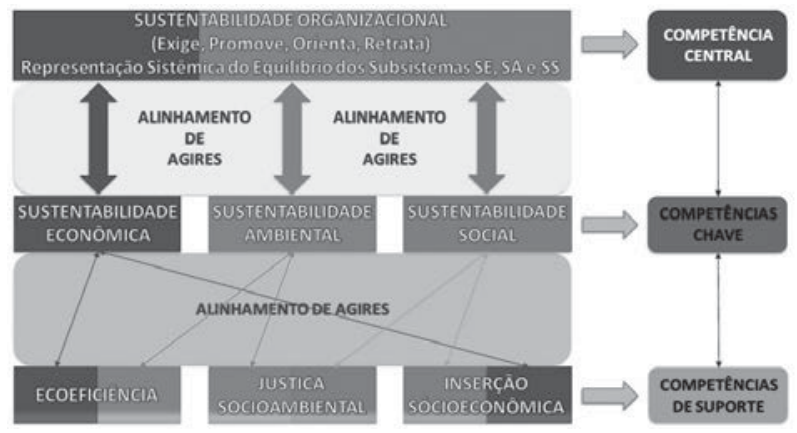

Figura 5: Framework representativo do acontecimento da Sustentabilidade Organizacional.

Fonte: Munck, Munck e Borim-de-Souza (2011, p. 155)

Munck, Munck e Borim-de-Souza (2011) constatam que as competências apresentam, de fato, potencial para orientar a gestão da sustentabilidade, mas se estiverem desarticuladas de suas premissas, gerarão processos desintegrados que tendem a acarretar em falta de coesão estratégica e, por conseguinte, prejuízos econômicos, sociais e ambientais. A sustentabilidade organizacional provém de um entendimento de desenvolvimento coletivo, com objetivos compartilhados, coordenados e em contexto de cooperação. Prioriza-se, assim, o âmbito das competências que constituem, em suma, o agir organizacional mobilizador de recursos e formador de uma cadeia de relacionamento capaz de retratar o caminho para o acontecimento da sustentabilidade organizacional, sem desconsiderar as influências externas.

Ao refletir sobre os cinco modelos apresentados, emergem aspectos convergentes e divergentes, suas fragilidades e avanços, apresentados na próxima seção.

\section{Análise Comparativa entre os Modelos Apresentados}

Com base nas três condições ideais para modelos de gestão da sustentabilidade, uma análise comparativa que apresenta convergências e divergências de cada modelo entre eles e em comparação com o quadro de análise será feita e, na sequência, serão apresentadas algumas pontuações críticas acerca de avanços e fragilidades de cada um dos cinco modelos expostos anteriormente, conforme a ordem em que foram apresentados.
Primeiramente, em relação ao Sistema de Gestão da Sustentabilidade Organizacional proposto por Azapagic (2003), com respeito a primeira condição, este modelo a atende completamente. Como ficou evidenciado em sua explicação e exposição, o sistema de gestão da sustentabilidade organizacional emerge e é incorporado dentro da visão e estratégia de negócios. Sobre a segunda condição, observou-se o seu atendimento parcial. Isso porque é comentada a necessidade de desenvolvimento de competências na etapa de implementação do sistema de gestão da SO, tendo em vista a decorrente mudança na cultura organizacional e nas atitudes dos empregados gerada por tal circunstância. Apesar disso, as competências em nível organizacional, que buscam retorno econômico, agregação de valor social e preservação ambiental, conforme indica o segundo parâmetro, não são explicitadas. Por último, a terceira condição pode ser considerada atendida em sua completude, tendo em vista as considerações do modelo acerca do longo prazo e do reconhecimento de implicações no âmbito de oportunidades rentáveis, tal qual a geração de vantagem competitiva.

No modelo de Redes Corporativas Sustentáveis Locais (SLENs) de Wheeler et al. (2005), tratando-se da primeira condição, notou-se que não fica explícita a maneira pela qual a sustentabilidade é implementada nas estratégias e operações das organizações envolvidas na rede. Da mesma forma, apesar de a atuação em redes poder ser considerada uma competência a ser desenvolvida por qualquer entidade que possa participar deste modelo de gestão da sustentabilidade, esta situação não é indicada e, além disso, não há um planejamento referente ao desenvolvimento de competências para a $\mathrm{SO}$, o que significa que este modelo não atende também a segunda condição. Já no que tange a terceira condição, pode-se afirmar que esta é atendida completamente, pois a atuação do modelo é voltada justamente para proporcionar retorno financeiro e sucesso no longo prazo, criando valor em termos econômicos, sociais, humanos e ecológicos. Contudo, embora aparentemente tenham uma característica marcadamente social, as redes parecem mais uma forma de manter as pessoas incluídas economicamente, o que não é suficiente para os princípios da sustentabilidade.

O Framework Balanced Scorecard Hexagonal de Cheng, Fet e Holmen (2010) atende completamente a primeira condição, haja vista pelos próprios recur- 
sos conceituais utilizados, BSC e Mapa Estratégico, a sustentabilidade é entendida e gerenciada do nível estratégico para o operacional, simultaneamente à agregação de aprendizados. No que diz respeito a segunda condição, pode-se dizer que este modelo a atende parcialmente. Assim como no caso do modelo de Azapagic (2003), o Framework Balanced Scorecard Hexagonal prevê o desenvolvimento de competências, habilidades e conhecimentos dos funcionários, bem como há a indicação de que a organização pode utilizar o meio ambiente e a sociedade como direcionadores de recursos e de desenvolvimento de capacidades. Entretanto, estas indicações são limitadas e as competências específicas para a SO não são mencionadas. Por fim, sobre a terceira condição, o modelo em pauta a atende completamente, uma vez que o ciclo contido apresenta a necessidade de avaliações contínuas e cíclicas a fim de que a organização possa adaptar e revisar sua estratégia a fim de sustentar seu desempenho no longo prazo.

A Síntese Socioeconômica, elaborada por Molteni e Pedrini (2010), atende completamente a primeira condição, uma vez que concerne a uma vasta gama de elementos organizacionais, desde processos únicos até orientações e processos estratégicos. Por outro lado, a segunda condição não é atendida, pois não há considerações no modelo que tratem de competências e ainda a inclusão da perspectiva ambiental se mostra de maneira rasa. Em relação a terceira condição, seu atendimento é verificado em completude, tendo em vista as prerrogativas do modelo de que este compreende soluções práticas que combinam alta competitividade e desempenho econômico com ótimos desempenhos sociais e ambientais e da necessidade de inovações contínuas para sustentação da empresa no tempo.

O último modelo apresentado, o framework representativo dos processos necessários ao acontecimento da SO de Munck, Munck e Borim-de-Souza (2011), atende por completo a primeira condição ao destacar que a SO como uma competência representa a operacionalização sistêmica dos recursos considerando os objetivos e estratégias organizacionais e as influências ambientais e que a desarticulação dessas premissas tende a acarretar em falta de coesão estratégica. Sobre a segunda condição, esta também é atendida completamente, o modelo em questão tem esclarecido que a validação das competências componentes da
SO permite um equilíbrio organizacional sistêmico e coordenado. Enfim, com relação à terceira condição, o modelo também a atende completamente, uma vez que por meio da gestão da SO via competências é possível fomentar e verificar a eficácia nos processos de ações e decisões organizacionais ao longo do tempo, contribuindo para o incremento da competitividade e lucratividade.

Com base no exposto e como forma de melhor apresentação dos resultados da análise dos modelos de sustentabilidade propostos apresentados neste artigo, o Quadro 5 foi desenvolvido. Os modelos são elencados e suas convergências ou não com os parâmetros destacados são representadas pelas siglas NA (não atende), $\mathrm{AP}$ (atende parcialmente) e $\mathrm{AC}$ (atende completamente).

\begin{tabular}{|c|c|c|c|}
\hline \multirow{2}{*}{$\begin{array}{c}\text { Modelos de Gestão dA } \\
\text { Sustentabilidade }\end{array}$} & \multicolumn{3}{|c|}{$\begin{array}{l}\text { PARÂMETROS } \\
\text { CONCEITUAIS }\end{array}$} \\
\hline & 1 & 2 & 3 \\
\hline $\begin{array}{c}\text { Sistema de gestão da } \\
\text { sustentabilidade organizacional } \\
\text { Azapagic (2003) }\end{array}$ & AC & AP & $\mathrm{AC}$ \\
\hline $\begin{array}{c}\text { Rede Corporativa Sustentável Local } \\
\text { Wheeler et al. (2005) }\end{array}$ & NA & NA & $\mathrm{AC}$ \\
\hline $\begin{array}{c}\text { Framework Balanced Scorecard } \\
\text { Hexagonal (BSH) } \\
\text { Cheng, Fet e Holmen (2010) }\end{array}$ & $\mathrm{AC}$ & $\mathrm{AP}$ & $A C$ \\
\hline $\begin{array}{l}\text { Síntese Socioeconômica } \\
\text { Molteni e Pedrini (2010) }\end{array}$ & $\mathrm{AC}$ & NA & $A C$ \\
\hline $\begin{array}{c}\text { Framework representativo } \\
\text { do acontecimento da } \\
\text { Sustentabilidade Organizacional } \\
\text { Munck, Munck e Borim-de-Souza (2011) }\end{array}$ & $A C$ & $\mathrm{AC}$ & $\mathrm{AC}$ \\
\hline
\end{tabular}

Quadro 5: Análise dos modelos de SO a luz das condições conceituais ideias

Fonte: Elaborado pelos autores deste artigo

Pela observação do Quadro 5, é perceptível que o único modelo que atende as três condições conceituais propostas simultaneamente é o framework representativo do acontecimento da Sustentabilidade Organizacional de Munck, Munck e Borim-de-Souza (2011). Em contraste, o modelo desenvolvido por Wheeler et al. (2005) é o único que atende completamente a apenas uma das condições, enquanto os outros três atendem a ao menos duas completamente. A partir dessas inferências, é possível apontar o modelo de gestão da sustentabilidade proposto por Munck, Munck 
e Borim-de-Souza (2011) como ideal, sendo um único critério o atendimento simultâneo a todas as condições conceituais ideais. No entanto, essas condições ideais elencadas ainda permitem pontuar avanços e fragilidades contidas no desenvolvimento de cada um dos cinco modelos apresentados, o que pode enriquecer tal constatação, corroborando-a ou refutando-a.

Sobre o Sistema de Gestão da Sustentabilidade Organizacional, proposto por Azapagic (2003), é possível especificar como avanços a determinação de que a sustentabilidade seja parte integrada da estratégia e visão organizacional, bem como a ênfase na mudança cultural da organização e mudança de atitude das personagens organizacionais. Acrescenta-se como um avanço do modelo a representação de um ciclo detalhado acerca da gestão da sustentabilidade iniciado pela política e planejamento da $\mathrm{SO}$, passando pelas estratégias de implementação, comunicação durante o processo de implantação e finalizado com a revisão seguida de ações corretivas, caso necessário.

Como uma fragilidade observada no modelo de Azapagic (2003), pontua-se que a sustentabilidade possa se tornar algo meramente instrumental na gestão, antes que uma "ideologia" para a organização, como o autor afirma constantemente. Isso devido ao fato de a sustentabilidade estar atrelada quase exclusivamente a estratégia produtiva (e não a estratégia de desenvolvimento de competências conforme proposto pelas condições conceituais ideais), a tornando, também, um instrumento de busca, quase que excepcionalmente, da lucratividade e do ganho de competitividade frente aos concorrentes.

Identificou-se como avanço no modelo de Redes Corporativas Sustentáveis Locais (SLENs) de Wheeler et al. (2005) o fato de que a criação de redes de colaboração entre diversos atores sociais é fundamental para o alcance do desenvolvimento sustentável, e nisso, a organização privada tem relevante participação. Importante da mesma forma é a identificação das várias âncoras envolvidas nas redes SLENs, desde indivíduos, organizações com e sem fins lucrativos, agências de desenvolvimento, governos, e comunidade local.

Além disso, este é um modelo que implica a necessidade de mudança de valores voltados para a cooperação. Para ser membro de uma rede do tipo SLEN, a organização necessita ter uma visão holística e compreender que interesses individuais não são prioridades, é preciso que todos os envolvidos atuem cooperativamente de acordo com os princípios da rede, a fim de que ela possa ser bem sucedida. Por outro lado, ao mesmo tempo em que se apresenta como um avanço, essa questão também pode representar uma fragilidade, pois, se os membros envolvidos não compactuarem de tais princípios, há a possibilidade de conflitos de interesses, com a predominância do individual ante ao coletivo. Uma vez que as redes são formadas por vários tipos de organizações, com interesses também diversos, não é algo improvável ou impossível que cada envolvido priorize e atue somente em seus domínios de prioridades individuais, contrariando e prejudicando o funcionamento da rede como um todo.

O terceiro modelo analisado, Framework Balanced Scorecard Hexagonal de Cheng, Fet e Holmen (2010) também possui seus avanços e fragilidades. Como avanços, apontam-se a utilização de um sistema interno de gestão já consolidado (BSC) que proporciona a gestão integrada e estratégica da SO por uma perspectiva interna à organização, assim como a estruturação e o detalhamento do modelo no sentido de que compreende a sua construção, difusão, aprendizagem e feedback da sustentabilidade organizacional, completando um ciclo, assim como o modelo de Azapagic (2003).

Porém, a fragilidade de tal modelo se resume no fato de que este é confuso ao apresentar questões que envolvem as perspectivas "Ambiental" e "Social", consideradas externas à organização pelas próprias autoras, apenas com foco interno à organização e ainda com um nível baixo de desenvolvimento. Ocorre que ambas as perspectivas demandam um tratamento mais amplo, tendo em vista que são questões que possuem impacto direto ao contexto externo da organização. Como posto pelas autoras, nota-se que tanto a perspectiva Ambiental quanto a Social são apenas novas áreas funcionais a serem inseridas na organização, $e$ não elementos que permeiam toda estratégia.

No que diz respeito ao modelo da Síntese Socioeconômica, proposto por Molteni e Pedrini (2010), os avanços se referem ao desenvolvimento do modelo com base na volatilidade inerente a gestão da SO. Os autores reforçam este pressuposto para o modelo ao argumentarem que o valor diferencial de uma síntese socioeconômica é provável de se perder com o tempo, havendo a necessidade de inovação constante. 
Um avanço importante no modelo refere-se ainda à hierarquia das soluções promovidas pela síntese socioeconômica, devido à inferência de que quanto mais envolvida está a organização com a gestão da sustentabilidade, maior é sua especificidade, maior é sua diferenciação frente aos concorrentes, logo, maior é seu nível de competitividade.

Como fragilidade, os autores parecem negligenciar a dimensão ambiental do TBL. Ainda que, no decorrer de seu texto mencionem as questões ambientais, na figura representativa da síntese socioeconômica somente são inseridas as dimensões social e econômica da SO. No framework representativo do acontecimento da sustentabilidade organizacional de Munck, Munck e Borim-de-Souza (2011), os avanços dizem respeito ao tratamento da sustentabilidade, bem como de seus fenômenos envoltos, a partir da lógica das competên- cias, concedendo à SO um meio de operacionalização e gerenciamento, da mesma forma que a aborda sob um prisma de integração sistematizada à estratégia organizacional. Aponta-se também a ênfase direcionada às pessoas neste processo. $\mathrm{O}$ modelo em questão tem como premissa que a ação coletiva, portanto, também a individual, é o alicerce de direcionamento da organização em busca da sustentabilidade.

Todavia, encontrou-se como uma fragilidade deste modelo a não inclusão na sua representação do ambiente externo à organização. Observou-se que os autores, em nenhum momento, fazem menção sobre o relacionamento com seus stakeholders externos o que pode deixar a organização isolada de seu contexto de atuação.

Como forma de simplificação e melhor visualização, no Quadro 6 é apresentado um resumo dos avanços e fragilidades apontados nos modelos estudados:

\begin{tabular}{|c|c|c|}
\hline \multirow{2}{*}{$\begin{array}{l}\text { Modelo } \\
\text { Sistema de Gestão } \\
\text { da Sustentabilidade } \\
\text { Organizacional } \\
\text { Azapagic (2003) }\end{array}$} & \multicolumn{2}{|l|}{ Avanços e Fragilidades } \\
\hline & $\begin{array}{l}\text { Avanços: } \\
\text { - Clareza da importância de que } \\
\text { a sustentabilidade faça parte da } \\
\text { estratégia e visão organizacional; } \\
\text { - Mudança cultural e de atitude; } \\
\text { - Apresentação de um ciclo: política, } \\
\text { planejamento, implementação, } \\
\text { comunicação, revisão e açôes corretivas. }\end{array}$ & $\begin{array}{l}\text { Fragilidade: } \\
\text { - A sustentabilidade pode se tornar algo meramente } \\
\text { instrumental, antes que uma 'ideologia' para a } \\
\text { organização, devido ao fato de estar atrelada quase } \\
\text { exclusivamente à estratégia organizacional, e não à } \\
\text { estratégia de desenvolvimento de competências. }\end{array}$ \\
\hline $\begin{array}{l}\text { Redes Corporativas } \\
\text { Sustentáveis } \\
\text { Locais (SLENs) } \\
\text { Wheeler et. al (2005) }\end{array}$ & $\begin{array}{l}\text { Avanços: } \\
\text { - A rede possuivárias âncoras; } \\
\text { - Proporciona visão macro } \\
\text { da sustentabilidade; } \\
\text { - Traz na sua essência, a necessidade } \\
\text { de mudança profunda de valores. }\end{array}$ & $\begin{array}{l}\text { Fragilidades: } \\
\text { - Possibilidade de conflitos de interesses e da } \\
\text { predominância do individual ante ao coletivo; } \\
\text { - Não demonstra como a sustentabilidade é implementada } \\
\text { nas estratégias e operações das organizações envolvidas; } \\
\text { - Não menciona o desenvolvimento } \\
\text { de competências para a SO. }\end{array}$ \\
\hline $\begin{array}{l}\text { Framework } \\
\text { Balanced Scorecard } \\
\text { Hexagonal }(\text { BSH) } \\
\text { Cheng, Fet e } \\
\text { Holmen }(2010)\end{array}$ & $\begin{array}{l}\text { Avanços: } \\
\text { - Traz a gestão da SO em um contexto } \\
\text { estratégico através do BSC; } \\
\text { - Apresentação de um ciclo: Construir, } \\
\text { Difundir, Aprender e Sustentar. }\end{array}$ & $\begin{array}{l}\text { Fragilidade: } \\
\text { - Aborda as perspectivas Ambiental e Social } \\
\text { como áreas funcionais da organização. }\end{array}$ \\
\hline $\begin{array}{l}\text { Síntese } \\
\text { Socioeconômica } \\
\text { Molteni e Pedrini (2010) }\end{array}$ & $\begin{array}{l}\text { Avanços: } \\
\text { - Necessidade de trabalhar em } \\
\text { novos projetos constantemente; } \\
\text { - Traz sete estágios de classificar a } \\
\text { intensidade em que a organização } \\
\text { está inserida na sustentabilidade. }\end{array}$ & $\begin{array}{l}\text { Fragilidade: } \\
\text { - Não demonstra explicitamente a } \\
\text { integração do pilar ambiental; } \\
\text { - Não faz menção ao desenvolvimento das } \\
\text { competências necessárias para o alcance da } \\
\text { sustentabilidade a partir da síntese socioeconômica. }\end{array}$ \\
\hline $\begin{array}{l}\text { Framework } \\
\text { representativo do } \\
\text { acontecimento da } \\
\text { Sustentabilidade } \\
\text { Organizacional } \\
\text { Munck, Munck e Borim- } \\
\text { de-Souza (2011) }\end{array}$ & $\begin{array}{l}\text { Avanços: } \\
\text {-Aborda a questão estratégica da SO, } \\
\text { por meio da lógica das competências; } \\
\text { - Foco nos indivíduos e no desenvolvimento } \\
\text { coletivo em contexto de cooperação; } \\
\text { - Prevê integração de objetivos } \\
\text { organizacionais e influências ambientais; } \\
\text {-Demonstra uma perspectiva sistêmica da SO. }\end{array}$ & $\begin{array}{l}\text { Fragilidade: } \\
\text { - Não faz menção explicita às formas de interação } \\
\text { com o ambiente externo à organização. }\end{array}$ \\
\hline
\end{tabular}

Quadro 6:Avanços e fragilidades dos modelos de SO estudados

Fonte: Elaborado pelos autores deste artigo 
A partir do Quadro 6, nota-se principalmente a incompletude dos modelos, no sentido de que todos demonstraram deixar algum aspecto descoberto, mas que seria importante para o alcance da SO. Dentre os avanços, o Framework representativo do acontecimento da Sustentabilidade Organizacional de Munck, Munck e Borim-de-Souza (2011) é o que apresenta um maior número e, em contraste com suas fragilidades, apenas uma é destacada. A análise sobre avanços e fragilidades dos modelos de gestão da $\mathrm{SO}$, complementada à análise sobre convergência e divergência com as condições conceituais ideais elencadas, permite a inferência de que o Framework representativo do acontecimento da Sustentabilidade Organizacional é o modelo com mais respostas às premissas da sustentabilidade ou o que menos falha neste sentido, dentre todos os analisados neste trabalho.

\section{Considerações Finais}

Desenvolveu-se este artigo com o objetivo de destacar e apresentar alguns modelos de gestão da sustentabilidade organizacional que relatassem a aplicação ou proposição de modelos de operacionalização da sustentabilidade em contexto organizacional. A partir de pesquisas em bases científicas legítimas, chegou-se a cinco modelos, elaborados no intervalo dos anos de 2003 a 2011, em diferentes localidades do mundo, selecionados pela sua originalidade. São eles: Sistema de Gestão da Sustentabilidade Organizacional (AZAPAGIC, 2003); Rede Corporativa Sustentável Local (WHEELER et al., 2005); Framework Balanced Scorecard Hexagonal (CHENG; FET; HOLMEN, 2010); Síntese Socioeconômica (MOLTENI; PEDRINI, 2010); e Framework Representativo do Acontecimento da Sustentabilidade Organizacional (MUNCK; MUNCK; BORIM-DE-SOUZA, 2011).

A partir da análise dos modelos, estabeleceram-se três condições conceituais ideais aos modelos de gestão da sustentabilidade nas organizações: a) a SO deve ser implementada como parte integral e contextual dos negócios por meio de sua inserção em decisões operacionais, táticas e estratégicas; b) a SO deve se pautar pelo desenvolvimento de competências que orientem a implementação e mensuração/acompanhamento que remetam para retornos econômicos, agregação de valor social e preservação ambiental. Sendo que os três elementos são atingidos, concomitantemente, considerando trade-offs; e c) a gestão da SO deve proporcionar respostas além das exigências legais que contribuam para a competitividade, lucratividade e para o sucesso das políticas consideradas sustentáveis no longo prazo. A partir destas condições, foram identificados convergências, pontos de avanços e fragilidades em cada um dos cinco modelos apresentados.

De forma geral, observou-se que os modelos reforçam o mainstream do TBL quando se trata da sustentabilidade nas organizações, ainda que suas três dimensões componentes não sejam explícitas ou consideravelmente trabalhadas por todos os modelos, de forma integrada e equilibrada. Constatou-se também a incompletude dos modelos, à medida que todos demonstraram falhar em algum aspecto que seria importante para o alcance da SO. Nota-se que a maioria dos modelos (Sistema de Gestão da Sustentabilidade Organizacional; Balanced Scorecard Hexagonal; e Síntese Socioeconômica) possui uma ênfase basicamente operacional e busca, principalmente, uma nova estratégia que levará a organização a uma posição de vantagem competitiva em relação aos concorrentes. O único modelo que exprime uma mudança mais ideológica - Redes Corporativas Sustentáveis Locais (SLENs) - (WHEELER et al., 2005) mostra-se de difícil aplicação por ser amplamente generalista em suas propostas. À exceção dos modelos de Wheeler et al. (2005) e de Munck, Munck e Borim-de-Souza (2011), para os quais a lucratividade e vantagem competitiva são respostas naturais à gestão da $\mathrm{SO}$, os outros três modelos analisados tem como foco principal a geração de lucros e vantagem competitiva.

A análise sobre avanços e fragilidades dos modelos de gestão da sustentabilidade organizacional complementada à análise sobre convergência e divergência com as condições conceituais elencadas como ideais e permite a inferência de que o último modelo avaliado - Framework Representativo do Acontecimento da Sustentabilidade Organizacional (FRASOR) de Munck, Munck e Borim-de-Souza (2011) - representa o modelo com mais respostas às premissas da sustentabilidade, se agregar explicações sobre as formas de interação com o meio poderá ser tornar uma boa referência para as organizações.

O referido modelo integra claramente as três dimensões, ou sustentabilidades da SO, retratando-as 
como competências organizacionais, de forma alinhada às estratégias e objetivos organizacionais, às intenções individuais e à abordagem integrativa do TBL. Ademais, este é um modelo genérico para vários tipos de organização, o que não dificulta sua adoção, seja por indústrias, comércios ou prestadoras de serviços. Por utilizarem uma teoria oriunda dos estudos organizacionais - a teoria do agir organizacional - a inserção das pessoas no processo de desenvolvimento da sustentabilidade se torna mais evidente por meio do alinhamento entre os agires, os quais representam a ação individual e coletiva. Ainda que não tenha sido inserida como uma condição conceitual ideal, a inserção das pessoas na gestão da SO parece fundamental. Entretanto, é preciso que sua fragilidade seja sanada, a fim de que o modelo avance em direção à sua consolidação e como um exemplo de framework global para a gestão sistêmica e estrutural da sustentabilidade organizacional.

Uma análise mais aprofundada permite identificar que a utilização de um modelo orientador da gestão da sustentabilidade na organização, como a proposta feita a partir do FRASOR, é pertinente por propiciar a unificação das interpretações divergentes que podem coexistir em uma mesma realidade, reduzindo a complexidade deste tópico e propiciando a busca deste objetivo comum, a sustentabilidade, em diversos níveis internos e externos às organizações. O entendimento comum, compartilhado e comprovado é condição para que este agir organizacional - a SO - seja efetivamente realizado, caso contrário, torna-se uma adversidade para toda a cadeia de ações dependentes. (MAGGI, 2006)

Além disso, a adoção e a utilização concisa de um modelo de gestão da sustentabilidade como o FRASOR pode contribuir para a imersão de novos valores relacionados à cultura organizacional, determinante para progressos da empresa neste âmbito e influenciada principalmente por investimentos em comunicação e compartilhamento de conhecimentos. Contribui ainda para a visão de cooperação, a partir da qual as premissas envoltas à sustentabilidade são passíveis de serem melhores e mais facilmente atendidas.

Um destaque interessante de ser notado é que o FRASOR - modelo considerado com mais respostas à SO na análise deste artigo - é um modelo brasileiro, cunhado a partir de observações de empresas nacionais e com foco em se tornar um modelo genérico com competências que são capazes de serem desenvolvidas em vários tipos de empresas. Porém, é possível que este modelo, quando aplicado, produza uma mudança cultural nas empresas com o entendimento de que a SO é uma estratégia incorporada nos objetivos e metas organizacionais. Contudo, apesar de observar que o nível de aplicação dos princípios da sustentabilidade no Brasil ainda é baixo e que na maioria das vezes se resume em cumprimento da legislação brasileira, a literatura nacional tem avançado satisfatoriamente neste aspecto.

Enfim, pelas considerações apresentadas, percebe-se a necessidade de maiores aprofundamentos quando se trata da implantação e operacionalização de modelos de gestão da sustentabilidade nas organizações. Sugere-se que novos modelos sejam encontrados $e$ analisados com o fim de ganhar referências para seus desenvolvimentos. Em suma, mostrou-se fundamental orientar-se não apenas pelos avanços, mas também pelas fragilidades apontadas na análise feita em diferentes modelos. Isso pode orientar aprimoramentos cabíveis ao desenvolvimento de um framework global unificador das boas experiências para a gestão sistêmica e estrutural da sustentabilidade organizacional. Do mesmo modo, sugere-se a realização de pesquisas empíricas, principalmente em relação à validação de modelos de gestão da $\mathrm{SO}$, a fim de que sejam evidenciadas suas contribuições tanto na teoria quanto na prática.

\section{REFERÊNCIAS}

ASIF, M. et al. Including sustainability in business excellence models. Total Quality Management \&

Business Excellence, Luleå, Suécia, v. 22, n. 7, p. 773786, 2011.

AZAPAGIC, A. Systems approach to corporate sustainability: a general management framework. Trans IChemE, Reino Unido, v. 81, n. 3, 2003.

BARBIERI, J. C. et al. Inovação e sustentabilidade: novos modelos e proposições. Revista de Administração de Empresas - RAE, São Paulo, v. 50, n. 2, 146-154, 2010.

BARKEMEYER, R. et al. What Happened to the 'Development' in Sustainable Development? Business Guidelines Two Decades After Brundtland. Sustainable Development, Malden, Estados Unidos, v. 22, p. 15-32, 2014. 
BARONI, Margaret. Ambigüidades e deficiências do conceito de desenvolvimento sustentável. Revista de

Administração de Empresas, São Paulo, v. 32, n. 2, p. 14-24, 1992.

\section{CALLADO, A. L. C. Modelo de mensuração de} sustentabilidade empresarial: uma aplicação em vinícolas localizadas na Serra Gaúcha. 2010. Tese (Doutorado em Agronegócios). Universidade Federal do Rio Grande do Sul. Porto Alegre, 2010.

CHENG, C. Y.; FET, A. M. HOLMEN, E. Using a Hexagonal Balanced Scorecard approach to integrate Corporate Sustainability into Strategy, Proceedings for the 16th International Sustainable Development Research Conference. Hong Kong, 2010.

DEMO, P. Pesquisa e construção do conhecimento: metodologia científica no caminho de Habermas. Rio de Janeiro: Tempo Brasileiro, 2000.

DIAS, B. G.; et al. Bases Compreensivas da Sustentabilidade Organizacional: a Proposição de uma Estrutura Conceitual (Framework). XIV SEMEAD - FEAUSP, São Paulo, 2011. Anais... SEMEAD, São Paulo, 2011.

DYLLICK, T.; HOCKERTS, K. Beyound the business case for corporate sustentability. Business Strategy and the environment, Malden, Estados Unidos, v. 11, p. 130$141,2002$.

ELKINGTON, J. Cannibals with forks: the triple bottom line of 21 st century business. Oxford: Capstone Publishing Limited, 1999.

\section{EPSTEIN, M. J. Making Sustainability Work: Best} Practices in Managing and Measuring Corporate Social, Environmental and Economic Impacts (Business). Greenleaf Publishing: UK, 2008.

EWEJE, G. A Shift in Corporate Practice? Facilitating Sustainability Strategy in Companies. Corporate Social Responsibility and Environmental Management, Malden, Estados Unidos, V. 18, p. 125-136, 2011.

HAHN, T.; SCHEEMESSER, M. Approaches to Corporate Sustainability among German Companies.

Corporate Social Responsibility and Environmental Management, Malden, USA, v. 13, n. 3, p. 121-181, 2006.
HOFF, D. N. A construção do desenvolvimento sustentável através das relações entre as organizações e seus stakeholders: a proposição de uma estrutura analítica. 2008. Tese (Doutorado em Agronegócios) Universidade Federal do Rio Grande do Sul, 2008.

JAMALI, D. Insights into the triple bottom line integration from a learning organization perspective. Business Process Management Journal, Bingley, Reino Unido, v.12, n. 6, p. 809-821, 2006.

LAVILLE, É. A empresa verde. São Paulo: ÕTE, 2009.

LORENZETTI, D. H.; CRUZ, R. M.; RICIOLI, S. Estratégia empresarial e sustentabilidade: um modelo integrador. Revista da Pós-graduação: Administração, Osasco, v. 2, n. 3, p. 33-57, 2008.

MAGGI, B. Do agir organizacional. São Paulo: Edgard Blücher, 2006.

MILLS, J. et al. Competing though competences. Cambridge: Cambridge University Press, 2002.

MOLTENI, M.; PEDRINI, M. In search of socio-economic syntheses. Journal of Management Development, Bingley, Reino Unido, v. 29, n. 7/8, p. 626-636, 2010.

MOHRMAN, S. A.; WORLEY, C. G. The organizational sustainability journey: Introduction to the special issue.

Organizational Dynamics, Bingley, Reino Unido, v. 39, p. 289-294, 2010.

MUNCK, L.; BORIM-DE-SOUZA, R. B. Gestão por competências e sustentabilidade empresarial: em busca de um quadro de análise. Gestão e Sociedade, Belo Horizonte, v. 3, n. 6, 2009.

Munck, L.; Munck, M. G. M.; Borim-de-Souza, R. Sustentabilidade organizacional: a proposição de uma framework representativa do agir competente para seu acontecimento. Gerais: Revista Interinstitucional de Psicologia, Juiz de Fora, v. 4, n. 2, ed. Especial, p. 147158, 2011.

SEARCY, C. Corporate Sustainability Performance Measurement Systems: A Review and Research Agenda. Journal of Business Ethics, Holanda, v. 107, p. 239253, 2012. 
SMITH, P. A. C.; SHARICZ, C. The shift needed for sustainability. The learning organization, Bingley, Reino Unido, v. 18, n. 1, p. 73-86, 2011.

STUBBS, W.; COCKLIN, C. Conceptualizing a

"Sustainability Business Model". Organization \&

Environment, Londres, Reino Unido, v. 21, n. 2, Jun.

2008.

VALENTE, M. Theorizing Firm Adoption of

Sustaincentrism. Organization Studies, Londres, Reino

Unido, v. 33, n. 4, p. 563-591, 2012.

VAN MARREWIJK, M. Concepts and Definitions of CSR and Corporate Sustainability: Between Agency and Communion. Journal of Business Ethics, Holanda, v. 44, n. 2-3, p. 95-105, 2003.

VAN MARREWIJK, M.; WERRE, M. Multiple Levels of Corporate Sustainability. Journal of Business Ethics, Holanda, v. 44, n. 2-3, p. 107-119, 2003.

VOS, R. O. Defining sustainability: a conceptual Orientation. Journal of Chemical Technology and Biotechnology, Malden, Estados Unidos, v. 82, n. 4, p. 334-339, 2007.

WHEELER, D. et al. Creating sustainable local enterprise networks. MIT - Sloam Management Review,

Cambridge, Massachusetts, v. 7, n. 41, 2005. 